\title{
LOS EFECTOS COLATERALES \\ DEL RÉGIMEN ALIMENTARIO
}

\section{Philip McMichael}

Darcy Tetreault plantea algunas preguntas clave en su atenta revisión de Regimenes alimentarios y cuestiones agrarias. Tuvimos la oportunidad de reunirnos y platicar de eso en el III Seminario de Estudios Críticos que se llevó a cabo en la Universidad Autónoma de Zacatecas en 2015. En ese momento, respondí a la pregunta quizás más significativa de Darcy, sobre el paradero de Alexander Chayanov. Dije bromeando que todavía no había tenido la oportunidad de leer El campesinado y el arte de la agricultura. Un manifiesto chayanoviano (2015), de Jan Douwe Van Der Ploeg, quien estaba sentado a mi lado. Más seriamente, esta aparente omisión requiere que aclare mi argumento.

Chayanov y la definición de «campesino» no aparecen en mi libro sobre los regímenes alimentarios porque no son particularmente relevantes en el argumento, que trata de la movilización campesina. Puesto que el libro tiene que ver con las contribuciones metodológicas que podemos derivar del análisis de los regímenes alimentarios, se enfoca en cómo los constructos analíticos que informan sobre la concepción clásica de la cuestión agraria son inadecuados. Además de repensar los términos de referencia de la cuestión agraria, Regímenes alimentarios explora cómo repensar las relaciones de valor alejándose de la asignación de precios a la labor humana y a los sistemas naturales y hacia una priorización del valor ecológico (utilizando estudios de agricultura agroecológica como ejemplos). ${ }^{1}$ El modo analítico clásico no sólo lleva consigo un thelos de teoría del valor con respecto al destino inevitable

${ }^{1} \mathrm{E}$ incorporando, desde luego, el análisis de Jan Douwe van der Ploeg sobre «recampesinización» (2009). 
del campesinado (ya sea por vía de desintegración o por diferenciación), sino también retrata a los campesinos como objetos de fuerzas económicas en lugar de sujetos históricos. En este modo los campesinos se representan categóricamente como residuales. Al mismo tiempo sus prácticas ecológicas son menospreciadas. Un análisis actualizado del régimen alimentario requiere revisar estas omisiones, y es así como el libro fue concebido. Pero mi explicación de las condiciones cambiadas de la cuestión agraria bajo el actual régimen alimentario corporativo/ neoliberal no está diseñada a restaurar el enfoque campesinista. Puede ser fácil leerla de esta manera, y por eso necesito responder.

El movimiento campesino contemporáneo no puede ser visto simplemente como una presencia campesina en sí misma. No se trata de si existen o no existen los campesinos o si ellos constituyen una nueva agencia revolucionaria. Ése es un debate que se encierra en sí mismo en un juego de tira y afloja entre dos extremos analíticos. Digo «extremos analíticos» porque es importante ir más allá de un debate estilizado como tal, enmarcado por un conjunto fijo de categorías analíticas. El último capítulo de Regímenes alimentarios es un argumento para ir más allá de la teoría ortodoxa del valor, reconociendo lo que se puede aprender del valor de las relaciones socioecológicas encarnadas en los sistemas diversos de agricultura de pequeña escala $-y$ lo que puede ampliarse mediante los vínculos urbano/rural- Es una crítica de cómo la teoría del valor ha sido entendida y aplicada, ${ }^{2}$ y por lo tanto cómo no permite ver a los campesinos como sujetos teóricos. Esto no quiere decir que debemos abandonar la teoría del valor, más bien significa que debemos usarla metodológicamente atendiendo a la historia política del capital -la cual es la fortaleza del análisis de los regímenes alimentarios-. El movimiento de soberanía alimentaria no se trata solamente de campesinos o alimentos, más bien tiene que ver con la violencia del régimen contemporáneo de comercio e inversiones en un contexto de inestabilidad social e incertidumbre ambiental seria. Se trata también de modelar las luchas

${ }^{2}$ Para una versión extendida de esta crítica, véase McMichael (2012), y Schneider y McMichael (2010). 
de abajo alrededor de principios democráticos, equidad de género, derechos de productores y prácticas ecológicas.

¿Qué quiero decir cuando digo que los campesinos son sujetos his tóricos? Como se subraya en Regímenes alimentarios, la movilización campesina es un producto del régimen alimentario corporativo. No se trata sencillamente de una movilización de productores de escala pequeña defendiendo su modo de vida. Un populista argumentaría esto. Y en efecto sería romántico, por decir lo mínimo, recomendar este modo de vida bajo las circunstancias actuales, tomando en cuenta los asaltos recientes manejados políticamente en contra de los medios de vida hogareños y en contra de las comunidades de agricultores pequeños, pescadores, pastores, habitantes de bosques y aun los trabajadores sin tierra. Debido precisamente al deterioro de la agricultura campesina/familiar en todo el mundo por medio del régimen alimentario, el movimiento de soberanía alimentaria basado en el campesinado emergió para llamar la atención sobre el empeoramiento de la condición de los productores de escala pequeña, quienes todavía constituyen una porción sustancial de la población global. Por cierto, no es el único grupo social que enfrenta privación y discriminación - pero esta condición contribuye a otras privaciones a través del proceso de desposesión, la flexibilización del trabajo y los circuitos forzados de labor (Araghi, 2000).

$\mathrm{El}$ análisis del régimen alimentario permite un entendimiento de por qué y cómo tal movilización campesina sucedió, en este momento, y con qué consecuencias. $\mathrm{Al}$ atender a la historia política del capital a través de la lente del régimen alimentario, se reconoce que la movilización campesina reciente no sólo se trata de la agricultura campesina. Más bien, provee una crítica general del capitalismo neoliberal y su régimen alimentario. Combina una crítica de la producción y también de las relaciones de circulación en el régimen alimentario industrial. Tiene que ver tanto con las condiciones laborales como con las condiciones geopolíticas, a través de las cuales un régimen instituido de comercio e inversión privilegia los agronegocios e inversionistas, para los cuales los productores de pequeña escala representan un obstáculo a la acumulación de capital. 
Adicionalmente, el movimiento campesino politiza el «comercio libre» y sus similares para la «seguridad alimentaria», y aboga por sistemas agrícolas alternativos de pocos insumos y regenerativos, protegidos o subsidiados por las autoridades públicas, y así contribuye al enfriamiento planetario. En otras palabras, el contramovimiento de soberanía alimentaria tiene implicaciones universales - y como nota Darcy no trata tanto de una condición de clase como de una identidad política dentro de una coyuntura histórica (donde los productores de escala pequeña se ven como redundantes o como instrumentos en la cadena de valor)-. La identidad política se deriva de la crítica más amplia incluida en el concepto de «soberanía alimentaria» (Patel, 2009; McMichael, 2014). Como observa el activista europeo de Vía Campesina, Paul Nicholson: «También es un proceso autónomo e independiente. No hay un comité central y la soberanía alimentaria no es el patrimonio de ninguna organización en particular. No es el proyecto de Vía Campesina o ni siquiera sólo un proyecto de los campesinos» (2009: 678-680).

Yo no veo este contramovimiento, originando en la movilización campesina, como chayanoviano. Tiene que ver con mucho más que la estabilización de un modo de producción campesino, con su lógica particular de equilibrios en el hogar. Encarna una politización del comercio neoliberal, las inversiones y las relaciones de propiedad intelectual en esta coyuntura histórica. Una intervención política como tal va mucho más allá que el hogar campesino de Chayanov, y se deriva de una coalición de fuerzas que incluye a los campesinos (comoquiera que se definan) entre otras agrupaciones sociales.

Desde mi punto de vista, el contramovimiento de soberanía alimentaria lleva consigo un mensaje civilizatorio fundamental. Es decir, no es sólo una crítica del capitalismo neoliberal, sino que ofrece una visión del mundo a partir de la cual se puede abordar la degradación del medio ambiente, el desplazamiento de millones de personas y la incertidumbre climática. Como tal, es un llamado por la reorganización de los Estados, las sociedades y la arquitectura del sistema internacional de Estados - alrededor de principios de ecología y sustentabilidad en lugar de los 
cercamientos y la financiarización-. Me refiero al movimiento basado en el campesinado con la metáfora del «canario en la mina» para subrayar que los que están más cerca de la tierra y de los cuerpos de agua son los que experimentan más agudamente la degradación de los ecosistemas (McMichael, 2008). Como tal, han tomado la responsabilidad de advertir al mundo. ¿Quién más puede hacer esto, y lo hacen —aparte del Papa, los activistas ecologistas y los científicos dedicados?

En estos términos, mi enfoque analítico del régimen alimentario lleva consigo dos afirmaciones: 1) que el contramovimiento de soberanía alimentaria representa y da voz a una visión esencialmente de largo plazo sobre la restauración de los paisajes agrícolas para la seguridad alimentaria global y el enfriamiento del planeta; y 2) que existe una necesidad inmediata para proteger y mejorar la capacidad de los productores de escala pequeña ${ }^{3}$ en todas partes del mundo, mismos que enfrentan en la actualidad a los asaltos corporativos coadyuvados por el Estado sobre su economía agrícola, además del cercamiento de su tierra y de sus recursos de propiedad común. Entonces la dinámica del régimen alimentario encarna un doble movimiento dentro del mismo contramovimiento: una lucha restaurativa inmediata por la gente de la tierra y también una visión restaurativa por el futuro de la humanidad.

En cuanto a las implicaciones, es importante reconocer la miríada de formas de experimentación colectiva de las comunidades que producen de la tierra y las aguas superficiales - como se ilustra en Regímenes alimentarios y en otros estudios que documentan las economías solidarias locales (véase por ejemplo Da Vía, 2012; Fonte, 2013, Andreé et al., 2014, Mann, 2014). La visión de soberanía alimentaria aboga por esta autonomía local y por la reorientación de los subsidios a la energía y a los agronegocios hacia el sostenimiento de la agricultura multifuncional, y por poner fin al «intercambio de alimentos» transfronterizo, no necesario y nocivo, que caracteriza al régimen alimentario corporativo.

${ }^{3}$ Los productores de escala pequeña son responsables por hasta 70 por ciento de los alimentos en el mundo (ETC, 2009) y por tanto son clave en la reducción de la inseguridad alimentaria. 
Una consecuencia del régimen alimentario del capital durante el último siglo y medio ha sido la monopolización progresiva de las regiones mundiales como graneros mundiales que exportan alimentos excedentarios a costa de los productores locales en otros lugares. La transformación resultante de las dietas globales incluye una profundización del consumo de proteínas animales, lo que amplía a los cereales forrajeros a costa de los granos alimentarios básicos. Ahora este modelo agroindustrial incluye cultivos para combustibles y otros cultivos de biomasa como insumos en bienes no alimentarios (como botellas basadas en plantas). Esta forma de «agricultura sin agricultores» (el concepto de Vía Campesina) alimenta a los ricos. Pero los sistemas alimentarios más equitativos reorientarían la producción de cereales hacia los objetivos sociales (alimentos primero) e inviertirían en formas de agroecología más productivas ${ }^{4}$ y resistentes. Para alcanzar esta meta, que incluye la revaluación del trabajo en la agricultura multifuncional, no se trata de una utopía campesina, sino de una tarea histórica para desmantelar un régimen alimentario basado en la conversión de la agricultura y sus paisajes y sistemas de agua en una forma singular de valor de cambio, orientado hacia la alimentación de los que tienen el poder de compra. Más que un proyecto campesino, esto involucrará la democratización radical de la gobernanza y la provisión de alimentos, el principio de alimentación primero (food first) acompañado únicamente con comercio justo, agricultura biorregional y la profundización de alianzas urbanasrurales, consejos para la política alimentaria, mercados locales, economías solidarias y poblados de transición en una era de descenso energético.

\section{BIBLIOGRAFÍA}

André́, Peter,Jeffrey Ayres, Michael Bosia y Marie-Josée Massicotte (eds.) (2014), Globalization and Food Sovereignty, Toronto, University of Toronto Press.

${ }^{4}$ La agricultura de pocos insumos es necesaria para restaurar los ecosistemas y ha sido identificada en el consenso científico reciente como suficiente para provisionar a la población mundial, si se valorizara adecuadamente y tuviera apoyo (por ejemplo, Badgley et al., 2007). 
Araghi, Farshad (2000), «The Great Global Enclosure of our Times: Peasants and the Agrarian Question at the end of the Twentieth Century», en F. Magdoff, J. B. Foster y F. H. Buttel (eds.), Hungry for Profit, Nueva York, Monthly Review Press.

Badgley, Catherine, Jeremy Moghtader, Eileen Quintero, E. Emily Zakem, M. Jahi Chappell, Katia Avilés-Vázquez, Andrea Samulon, Ivette Perfecto (2007), «Organic Agriculture and the Global Food Supply», Renewable Agriculture and Food Systems, vol. 22, núm. 2, pp. 86-108.

DA Vía, Elisa (2012), «Seed diversity, farmers' Rights, and the Politics of Repeasantization», International Journal of Sociology of Agriculture and Food, vol. 19, núm. 2, pp. 229-242.

ETC (2009), «Who Will Feed Us?», ETC Group Communiqué 102. www.etcgroup. org

Fonte, Maria (2013), «Food Consumption as Social Practice: Solidarity Purchasing Groups in Rome, Italy», Journal of Rural Studies, vol. 32, pp. 230-239.

Nicholson, Paul (2009), «Interview with Hannah Wittman», Journal of Peasant Studies, vol. 36, núm. 3, pp. 676-682.

Mann, Alana (2014), Global Activism in Food Politics. Power Shift, Houndsmill, Palgrave Macmillan.

McMichael, Phillip (2008), «The peasant as «Canary»? Not too Early Warnings of Global Catastrophe», Development, vol. 51, núm. 4, pp. 504-511.

(2012), «In the Short Run are we all Dead? A Political Ecology of the Development Climate», en R. Lee (ed.), The Longue Dureé and World-Systems Analysis, Albany, Suny Press.

(2014), «The Food Sovereignty Lens», en P. Andreé, J. Ayres, M. Bosia y M.-J. Massicotte (eds.), Globalization and Food Sovereignty, Toronto, University of Toronto Press.

Patel, Raj (2009), «Food Sovereignty», The Journal of Peasant Studies, vol. 36, núm. 3, pp. 663-706.

Ploeg, Jan Douwe, van der (2009), The New Peasantries. Struggles for Autonomy and Sustainability in an Era of Empire and Globalization, Londres, Earthscan.

(2015), El campesinado y el arte de la agricultura. Un manifiesto chayanoviano, México, Miguel Ángel Porrúa, uAz.

Schneider, Mindi y Phillip McMichael (2010), «Deepening, and Repairing, the Metabolic Rift», The Journal of Peasant Studies, vol. 37, núm. 3, pp. 461-484. 
